ISSN: 1980-055X

Recebido em: 30/04/2010

Aceito para publicação em: 22/07/2010

\title{
DENGUE: UMA ANÁLISE CLIMATO-GEOGRÁFICA NA CIDADE DE JATAÍ-GO
}

\author{
Clarissa Cardoso Pereira ${ }^{21}$ \\ Zilda de Fátima Mariano 22 \\ José Ricardo Rodrigues Rocha ${ }^{23}$
}

\begin{abstract}
RESUMO
Os atuais estudos de geografia da saúde vêm abordando, principalmente, a influência do meio geográfico, as alterações ambientais e a organização social, sobre a saúde e qualidade de vida das pessoas. Esses estudos, em sua maioria, visam contribuir com os programas de saúde pública e de planejamento ambiental urbano. Nesse sentido, este presente artigo tem como objetivo analisar a variabilidade da precipitação pluvial com o número de casos de dengue no município de Jataí-GO, no período de 2007 a 2009. Foram instaladas estações automáticas para mensuração dos elementos climáticos como temperatura do ar e umidade do ar e pluviômetros para a coleta da precipitação pluvial, em vários pontos no perímetro urbano. Esses dados foram tabulados e correlacionados com os casos confirmados de dengue. Desta forma, no período de 2007 a 2009, ocorreu grande variabilidade na distribuição da dengue nos bairros. Os maiores números de casos se concentraram na região do Centro Técnico Sucam, com 181 de ocorrências, de um total de 703 casos registrados, correspondendo a 26\%. O bairro Centro e Vila Fátima foram os que apresentaram o maior número de casos, registrando 49 e 89 casos de dengue respectivamente. Em seguida o setor Aeroporto com o registro de 39 casos de dengue. Embora o mês de março fosse o mais chuvoso (acima de $320 \mathrm{~mm}$ ), os maiores números casos de dengue ocorreram após o mês de março, nos meses de abril (109 casos) e maio (107), pois é neste período em que há uma diminuição das chuvas e do escoamento superficial, além acúmulo de água nos recipientes que favorecem a proliferação de larvas, confirmado por Silva (2006 e 2007). A partir dos resultados obtidos, consideramos que o mosquito transmissor da dengue vem, ao longo do tempo, se adaptando ao meio urbano, pois, é neste ambiente que encontra as condições ambientais e sociais ideais para a sua procriação. Os maiores índices de casos de dengue em Jataí seguem um padrão sazonal na estação do verão e outono, principalmente nos meses de

21 Licenciada em Geografia e Discente do Curso de Bacharelado em Geografia Universidade Federal de Goiás, Campus Jataí, E-mail: clarissageo@gmail.com

22 Professora Adjunta, Universidade Federal de Goiás. E-mail: zildamariano@hotmail.com

23 Bolsista PIBIC - Programa Institucional de Bolsas de Iniciação Cientíca-UFG-Ca Universidade Federal de Goiás, Campus Jataí. E-mail: joserocha90@hotmail.com
\end{abstract}


março, abril e maio com condições ambientais propiciam ao desenvolvimento dos ovos do mosquito Aedes aegypti.

Palavras-chave: dengue, temperatura do ar, precipitação pluvial, Jataí-GO, urbano.

\section{ABSTRACT}

Current studies are addressing health geography, especially the influence of geographical environment, environmental change and social organization on health and quality of life. These studies, mostly aimed at contributing to the programs of public health and urban environmental planning. Thus, this present article aims to analyze the variability of rainfall with the number of dengue cases in the municipality of Goiás-GO, in the period 2007 to 2009. Automatic stations were installed to measure the climatic elements such as air temperature and air humidity and rain gauges for the collection of rainfall at various points within the city limits. These data were tabulated and correlated with confirmed cases of dengue. Thus, in the period 2007-2009, there was great variability in the distribution of dengue in the neighborhoods with the highest numbers of cases were concentrated in the region of Sucam Technical Center, with 181 occurrences, of a total of 703 registered cases, accounting to $26 \%$. The neighborhood center and Vila Fátima were the neighborhoods where the highest number of cases recorded 49 dengue cases and 89 respectively, followed by the Airport with the record of 39 cases of dengue. Although the month of March was the wettest (above $320 \mathrm{~mm}$ ), the highest dengue cases begin after the month of March, the months of April and May the highest rate of occurrence of dengue, 109 and 107 respectively, for this period there is a decrease in rainfall and the accumulation of water in containers and reducing the runoff favoring proliferation, confirmed by Silva (2006 and 2007). From the results obtained, we believe that the principal mosquito that transmits dengue has, over time, adapting to the urban environment, then, is this environment that meets the environmental and social conditions ideal for its breed. The highest rates of dengue in Jataí follow a seasonal pattern in the summer season and autumn, especially during March, April and May with environmental conditions conducive to the development of eggs of the mosquito Aedes aegypti.

Key words: dengue, air temperature, rainfall, Goiás-GO e urban.

\section{INTRODUÇÃO}

Com o rápido crescimento populacional das áreas urbanas e as explorações dos recursos naturais, decorrente da Revolução Industrial, que ocorrem de forma desordenada e desigual diante das medidas do homem capitalista em produzir, as cidades cresceram desordenadamente e as condições de vida das pessoas se agravaram.

Sob o impacto da industrialização, Rosen (1994), citado por Costa (2001, p.15) destaca que as cidades se desenvolveram em um ritmo cada vez mais 
veloz, e não se conseguiu controlar ou regular esse processo, fazendo com que os males suplantessem os benefícios iniciais.

As modificações produzidas na natureza de forma equivocada pelo homem, ou seja, alteração através de intervenções como a poluição de automóveis, indústrias e a produção de energia pelas edificações, influenciam os meio internos urbanos, que contribui de forma negativa ou positiva para a qualidade de vida e ambiental da população (PAULA, 2004).

Mas, não é de hoje que o homem vem estudando a relação do ambiente e a saúde humana, na obra Ares, Águas e Lugares de Hipocrátes, o pai da medicina, descreveu a estreita relação entre ambiente e saúde, desde a Grécia Antiga e posteriormente Hipócrates, destacou os estudos dos ambientes urbanos e qualidade de vida nas cidades (COSTA, 2001).

O clima é um elemento ambiental que exerce forte influencia na saúde humana de forma positiva e negativa. A temperatura do ar, precipitação pluviométrica e a umidade do ar influenciam sobre as manifestações de diversas doenças.

Devido ao constante contato com o meio ambiente atmosférico, através de trocas térmicas, hídricas e gasosas, o corpo humano é influenciado pelos parâmetros climáticos temperatura do ar, umidade, precipitação, pressão atmosférica e ventos afetam a saúde humana de forma direta (sensação de conforto, mortalidade e morbidade por doenças sistêmicas) e indireta (doenças infecciosas transportadas por vetores ar, água, solo e alimentos), (PINTON E DOMINGOS, 2004).

Os impactos climáticos sobre a saúde humana podem ser apreciados através dos eventos meteorológicos extremos, causando acidentes e/ou por meio da disseminação de vetores e patógenos, com conseqüente transmissão de doenças infecciosas (Confalonieri, 2003).

Ainda segundo este autor, no que diz respeito à saúde humana sobre a influência de eventos climáticos:

[...] temos os fatores tais como temperatura, umidade relativa, precipitação pluviométrica e até o ciclo hidrológico afetando a capacidade de reprodução e sobrevivência de agentes patogênicos no meio ambiente e, principalmente, dos chamados vetores de agentes infecciosos, tais como os mosquitos envolvidos na transmissão da malária, da febre da dengue etc. (Confalonieri, 2003, p. 193)

Para Ayoade (1996), a saúde humana, energia e o conforto são afetados mais pelo clima do que por qualquer outro elemento do meio ambiente. $\mathrm{E}$ aliado a influência do clima e os maus hábitos humanos, no que tange ao saneamento urbano, tem-se intensificado doenças de inseto-parasitário como é o caso da febre amarela, malária e a dengue.

A dengue é uma doença que afeta grande parcela da humanidade. $\mathrm{E}$ tornou-se um dos principais problemas de saúde pública no mundo, e tem uma maior proliferação em regiões tropicais em razão do clima quente e úmido. Esse fato reforça a afirmação de Ayoade (1996) de que algumas doenças tendem a ser predominantemente em certas zonas climáticas, enquanto que outras, particularmente as contagiosas tendem a seguir um padrão sazonal em sua tendência. 
Além da relação da dengue com as condições climáticas e a proliferação em país tropical segundo Silva (2007), estudos têm provado que as condições sócio-ambientais destes países também são favoráveis à proliferação do vetor transmissor da dengue.

Os casos notificados de dengue, ao passar dos anos, vem aumentando no Brasil. Em 2009 foram notificados 361.552 casos de dengue no país, com $77,7 \%$ dos casos concentrados em sete estados. No Estado de Goiás, de acordo com os dados de 2009, os 219 munícipios goianos tiveram 44.083 casos, no qual dez municípios apresentaram 35.795 casos. O municipio de Jataí está em décimo lugar, com $\mathbf{3 7 5}$ notificações de casos de dengue. (SUPERINTENDÊNCIA DE POLÍTICAS DE ATENÇÃO INTEGRAL A SAÚDE GERÊNCIA DE VIGILÂNCIA EPIDEMIOLÓGICA, 2010).

Os atuais estudos da Geografia da Saúde vêm abordando, principalmente, a influência do meio geográfico, das alterações ambientais e da organização social, sobre a saúde e qualidade de vida das pessoas. Esses estudos, em sua maioria, visam contribuir com os programas de saúde pública e de planejamento ambiental urbano.

Dessa forma há necessidade de avaliações e identificação dos bairros com maiores casos, buscando definir as causas e sugerindo modos de planejamento da cidade e educação ambiental que minimizem ou melhorem os problemas gerados pela dengue. Assim, a cidade de Jataí, precisa de informações que contribuam com as atividades da Vigilância Epidemiológica, principalmente em relação à identificação dos maiores locais de proliferação para um planejamento na política pública de combate.

Nesse sentido, este presente artigo tem como objetivo analisar a relação da precipitação pluvial com o número de casos de dengue no município de JataíGO, no período de 2007 a 2009.

\section{MATERIAS E MÉTODOS}

A cidade de Jataí está situada na microrregião do sudoeste de Goiás, no estado de Goiás, mapeado nas folhas SE - 22 - V - D (IBGE, 1982) e SE - 22 Y - B (IBGE, 1978) foi emancipada em 1888, hoje apresenta uma população total de 81.972 habitantes, onde $91 \%$ do total de habitantes do município residem na área urbana, (IBGE, 2007). A cidade de Jataí possui mais de 72 bairros.

Foram instaladas estações automáticas no perímetro urbano da cidade para mensuração de dados de temperatura do ar e umidade do ar e pluviômetros para a precipitação pluvial, nas localidades: Posto Delta, Unidade Jatobá, Unidade Riachuelo, Clube dos Sargentos, Comercial Dudu, Centro Técnico Sucam e Centro/Sucam, com o objetivo de caracterizar o clima urbano, primeiramente partir da análise do conforto térmico e em 2006 iniciou a análise da relacão entre o clima e doenças respiratórias e a dengue. As estações automáticas utilizadas foram para este presente artigo foram: Clube dos Sargentos, Comercial Dudu, Centro Técnico Sucam e Centro/Sucam, identificadas na figura 1. 


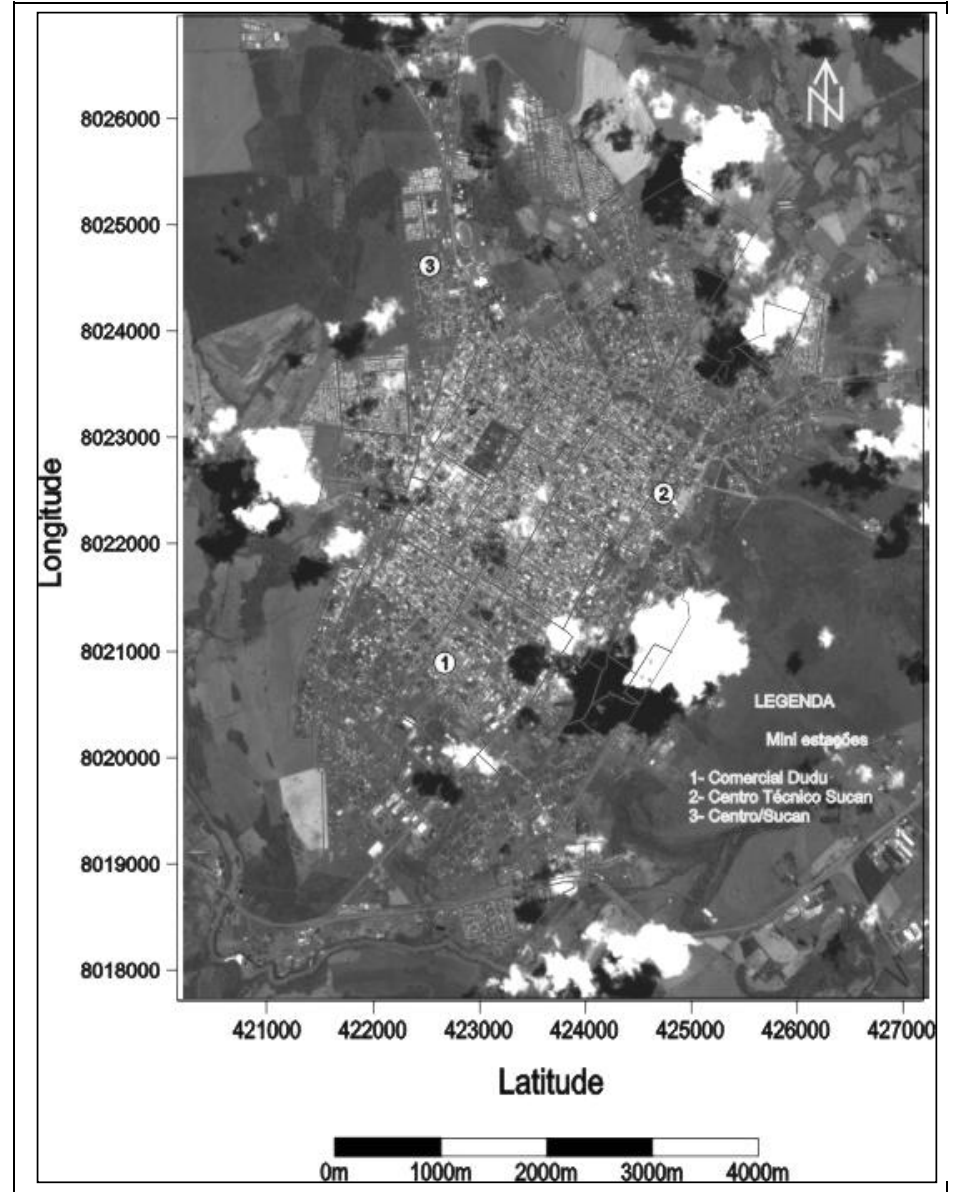

Figura 1 - Localização das estações automáticas em Jataí-Go

Os dados dos casos confirmados de dengue foram fornecidos pela Vigilância Epidemiológica da Secretaria Municipal de Saúde de Jataí. A partir desses dados foram calculados as frequências simples e estabelecido os valores de classes baseado em Assis, et al (1996, p. 17). Posteriormente os dados foram espacializados no Corel Draw,(Tabela 1).

Tabela 1-Determinação das classes em relação aos números de casos, confirmados de dengue-Jataí/GO.

\begin{tabular}{|c|c|c|}
\hline CLASSES & No DE CASOS & \\
\hline $\mathbf{1}$ & Sem registro & \\
\hline $\mathbf{2}$ & 1 a 5 & \\
\hline $\mathbf{3}$ & 6 a 10 & \\
\hline $\mathbf{4}$ & 11 a 20 & \\
\hline $\mathbf{5}$ & 21 a 30 & \\
\hline $\mathbf{6}$ & 31 a 35 & \\
\hline $\mathbf{7}$ & Acima de 35 & \\
\hline
\end{tabular}


Para a relação entre os casos confirmados de dengue com a precipitação pluvial, consideraram-se as três estações automáticas localizadas em pontos do perímetro urbano, as quais cada uma corresponde a um conjunto de bairros com casos confirmados de dengue (Tabela $\mathbf{2}$ ). O primeiro ponto é o Comercial Dudu, (Figura 1), situado numa avenida, totalmente pavimentada e com intenso movimento de veículos, embora tenha uma praça com árvores. O segundo ponto é o Centro/Sucam, com grande movimento de veículos, concentração bancária e comercial, totalmente pavimentado e localiza numa rua paralela a avenida principal da cidade (Av. Goiás), e o terceiro o Centro Técnico Sucam, apresenta poucas ruas pavimentadas e pouco movimento de veículos e muitas árvores.

Tabela 2 - Estações automáticas e seus respectivos bairros de abrangência

\begin{tabular}{|c|c|}
\hline Estação automática & BAIRROS \\
\hline Comercial Dudu & Vila Fátima, Vila Palmeira, Vila Progresso e Jardim Rio \\
Claro.
\end{tabular}

\section{RESULTADOS E DISCUSSÃO}

\section{Distribuição das chuvas no perímetro urbano de Jataí}

O clima de Jataí apresenta características semelhantes ao clima do Sudoeste Goiano: clima tropical, com duas estações bem definidas, um verão quente e chuvoso, com chuvas de outubro a março e um inverno seco e frio, com seca de abril a setembro.

As chuvas no perímetro urbano tiveram uma variação expressiva. No ano de 2007, choveu mais no Centro Técnico Sucam (1751 mm). Em 2008 e 2009 a localidade Comercial Dudu teve o maior valor pluviométrico com 1918 e 1742 $\mathrm{mm}$, respectivamente. A localidade Centro Técnico Sucam situada a norte e o Comercial Dudu ao sul, mostrando um decréscimo das chuvas no sentido sul para norte da cidade, (Tabela $\mathbf{3}$ ).

Tabela 3 - Dados de chuvas, no perímetro urbano de Jataí-GO

\begin{tabular}{|l|l|l|l|l|}
\hline Ano & Centro Sucam & Comercial Dudu & $\begin{array}{l}\text { Clube } \\
\text { Sargentos }\end{array}$ & $\begin{array}{l}\text { Centro } \\
\text { Técnológico } \\
\text { Sucam }\end{array}$ \\
\hline 2007 & 1387 & 1512 & 1292 & 1751 \\
\hline 2008 & 1677 & 1918 & 1216 & 1519 \\
\hline 2009 & 1494 & 1742 & 1162 & 1584 \\
\hline
\end{tabular}

Em relação às chuvas no ano de 2007, o total pluviométrico nas quatro localidades foi acima de $1292 \mathrm{~mm}$. Na localidade Clube dos Sargentos (1292 $\mathrm{mm}$ ) o período chuvoso foi de janeiro a março. Nas localidades Comercial Dudu e Centro Sucam (1387 mm) durante o período de janeiro a maio. Na localidade 
Centro Técnico Sucam (1751 mm) as chuvas ocorreram até o mês de junho. 0 mês mais chuvoso foi janeiro, com 459 mm, figura 2.

No ano de 2008, o período chuvoso foi de janeiro a maio e o total pluviométrico nas quatro localidades foi acima de $1216 \mathrm{~mm}$, com a seguinte distribuição nas localidades: Clube dos Sargentos $(1216 \mathrm{~mm})$, Comercial Dudu $(1918 \mathrm{~mm})$, Centro Sucam $(1677 \mathrm{~mm})$ e Centro Técnico Sucam $(1519 \mathrm{~mm})$. O mês mais chuvoso foi março, com 367 mm, figura 3.

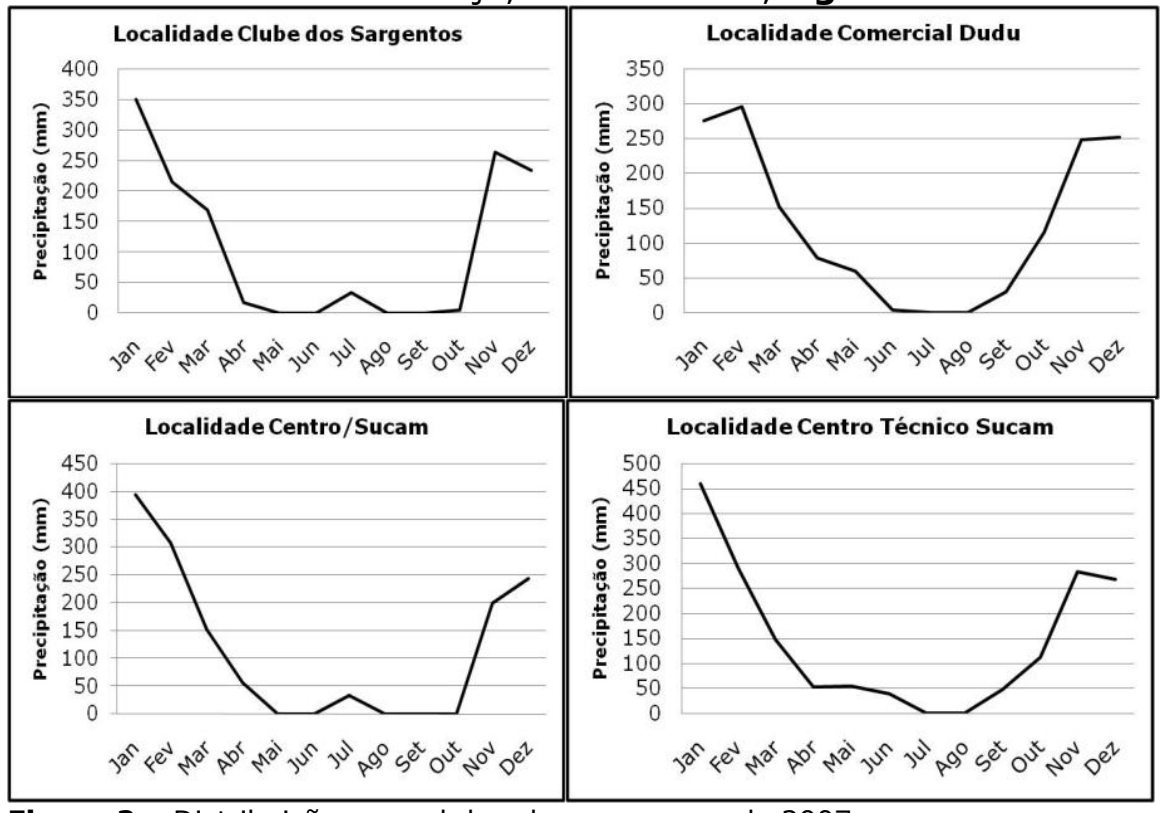

Figura 2 - Distribuição mensal das chuvas, no ano de 2007.

Fonte de Dados: Estações automáticas do Projeto "O Clima Urbano de Jataí" (Laboratório de Climatologia-UFG/Campus Jataí)

Organizado por: PEREIRA, 2010.

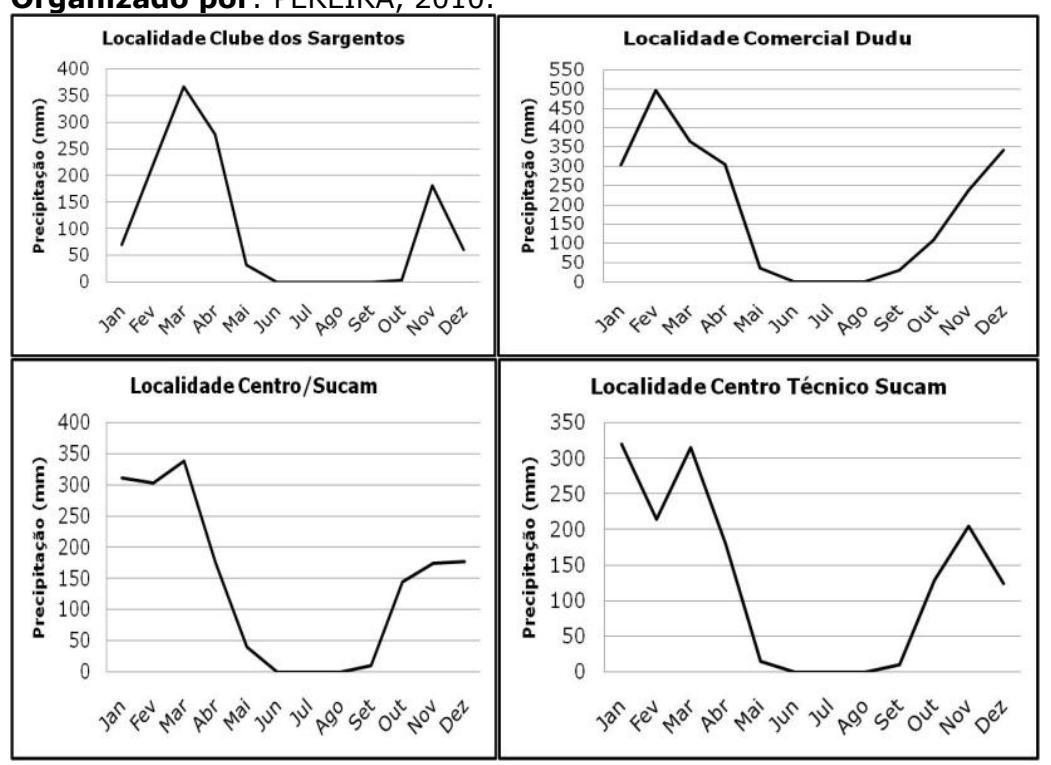

Figura 3 - Distribuição mensal das chuvas, no ano de 2008

Fonte de Dados: Estações automáticas do Projeto "O Clima Urbano de Jataí" (Laboratório de Climatologia-UFG/Campus Jataí)

Organizado por: PEREIRA, 2010. 


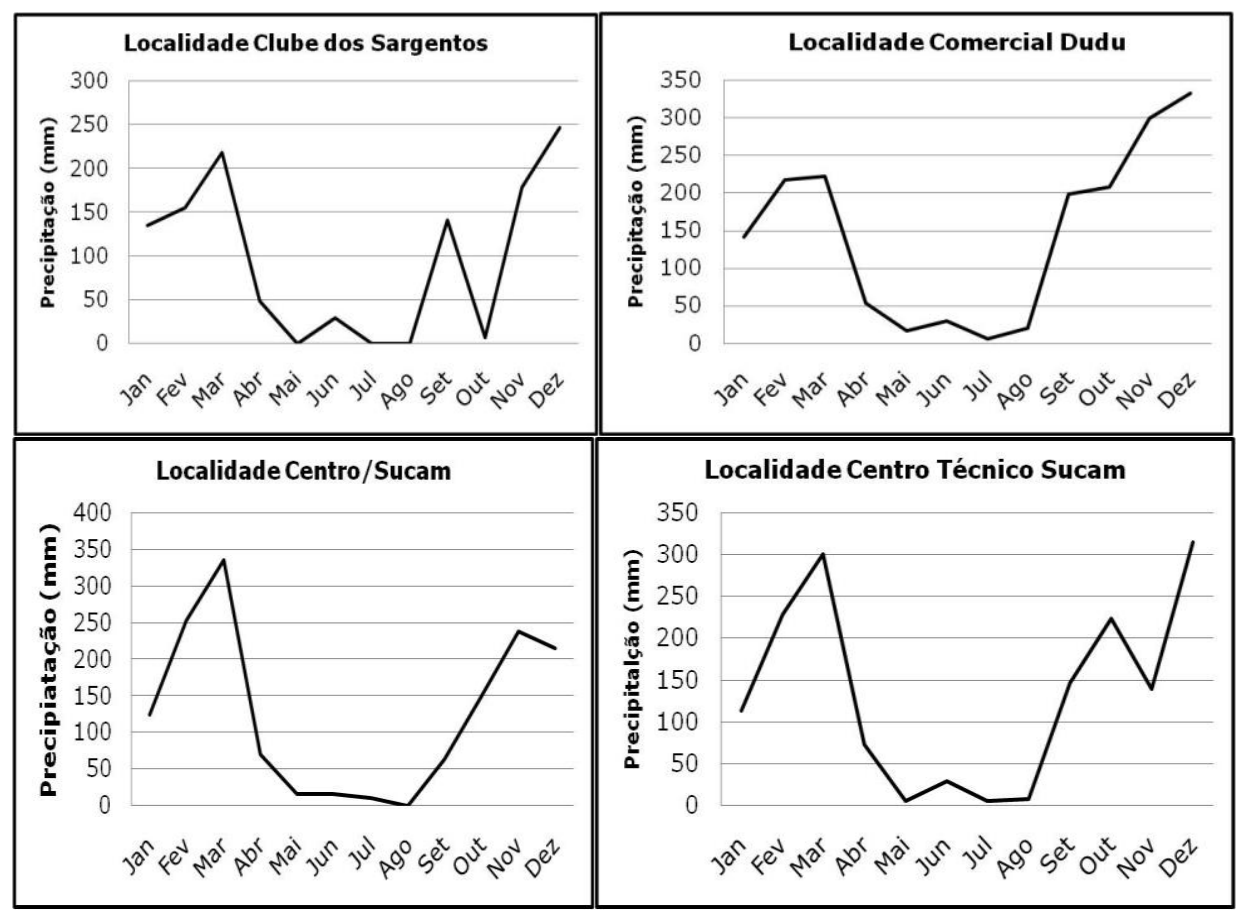

Figura 4 - Distribuição mensal das chuvas, no ano de 2009.

Fonte de Dados: Estações automáticas do Projeto "O Clima Urbano de Jataí" (Laboratório de Climatologia-UFG/Campus Jataí)

Organizado por: PEREIRA, 2010.

Em 2009 verificamos que as chuvas ocorreram entre de janeiro a maio e de agosto a dezembro, o qual foi registrado o total pluviométrico nas quatro localidades acima de $1162 \mathrm{~mm}$ : o Clube dos Sargentos (1162 mm), Comercial Dudu (1742 mm), o Centro Sucam (1494 mm) e Centro Técnico Sucam (1584 mm). O mês de março foi o mês mais chuvoso, com 335 mm, Figura 4.

\section{Distribuição da dengue na cidade de Jataí}

No Estado de Goiás, no ano de 2009, os 219 munícipios goianos apresentaram 44.083 casos, desses dez municípios tiveram $\mathbf{3 5 . 7 9 5}$ casos. O município Jataí obteve o décimo lugar com 375 notificações, (SUPERINTENDÊNCIA DE POLÍTICAS DE ATENÇÃO INTEGRAL A SAÚDE GERÊNCIA DE VIGILÂNCIA EPIDEMIOLÓGICA, 2010).

Na cidade de Jataí, o índice de casos de dengue confirmados tem seguido um padrão sazonal, com ocorrência principalmente no período de verão, outono e inicio do inverno, com exceção do ano de 2009, que apresentou casos em todos os meses.

No ano de 2007 foram confirmados 224 casos de dengue, os maiores casos de dengue ocorreram nos meses de maio (57), junho (46) e abril (36), na estação de outono, devido à água acumulada após a estação mais chuvosa. 


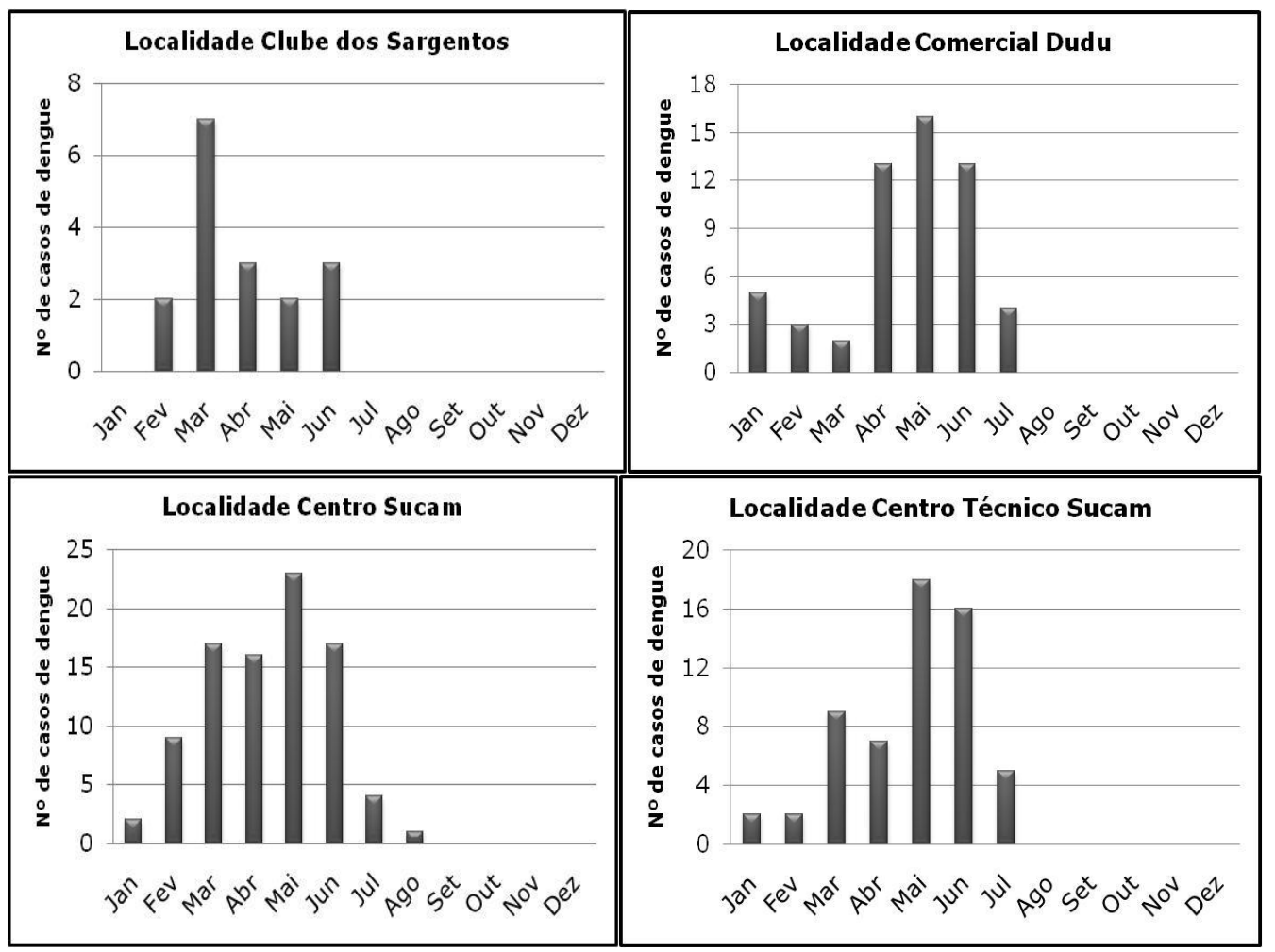

Figura 5- Distribuição mensal dos casos de dengue, no ano de 2007

Fonte de Dados: Secretaria Municipal de Saúde - Vigilância Epidemiológica e Projeto "O Clima Urbano de Jataí" (Laboratório de Climatologia-UFG/Campus Jataí)

Organizado por: PEREIRA, 2010.

Os casos de dengue na localidade Clube dos Sargentos ocorreram de fevereiro a junho, com 19 casos. A localidade Comercial Dudu teve 55 casos entre os meses janeiro a junho. As localidades Centro Sucam (90) e o Centro Técnico Sucam (60) apresentaram a maior ocorrência, de janeiro a agosto. No bairro Centro constatou-se os maiores casos de dengue, com 35 casos, devido às calhas de casas e imóveis fechados, Figura 5. Embora, março foi o mês mais chuvoso, os maiores casos de dengue iniciaram após neste mês. Esse comportamento deve-se pela diminuição das chuvas, aliados à diminuição do escoamento superficial da água e ao acúmulo de água em recipientes que, favorece a proliferação das larvas do Aedes aegypti, confirmados por Silva (2006 e 2007).

No ano 2008 as ocorrências de dengue somaram 66 casos, no qual a maior ocorrência foi na localidade Centro Técnico Sucam, no bairro aeroporto. $\mathrm{Na}$ localidade Clube dos Sargentos ocorreram 8 casos, desses 4 casos ocorreram no mês de maio. A localidade Comercial Dudu apresentou 16 casos, sendo abril o mês com maior ocorrência (6 casos). Na localidade Centro Sucam foram registrados 15 casos. O maior número de casos ocorreu na localidade Centro Técnico Sucam, com 27 casos e desses 11 casos no mês de março, figura 6 . 


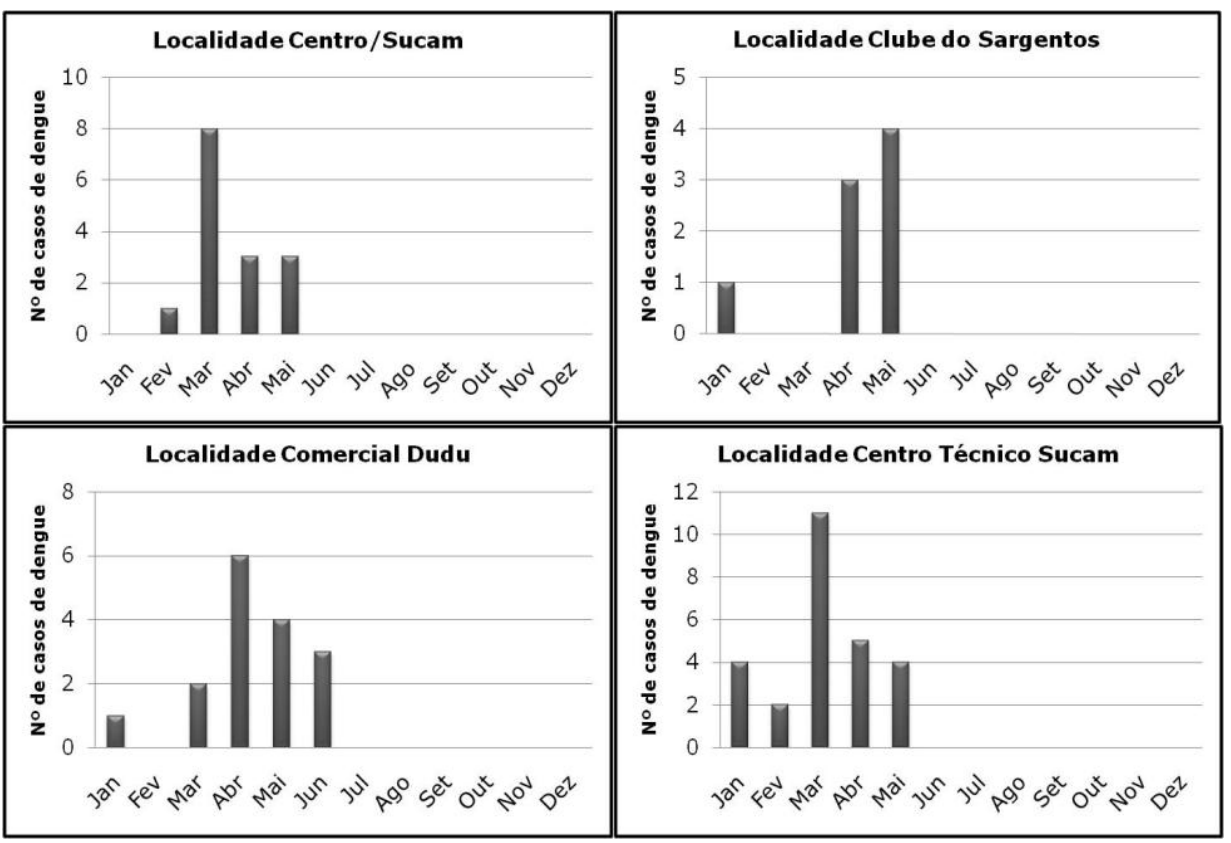

Figura 6 - Distribuição mensal dos casos de dengue, no ano de 2008

Fonte de Dados: Secretaria Municipal de Saúde - Vigilância Epidemiológica e Projeto "O Clima Urbano de Jataí" (Laboratório de Climatologia-UFG/Campus Jataí)

Organizado por: PEREIRA, 2010.

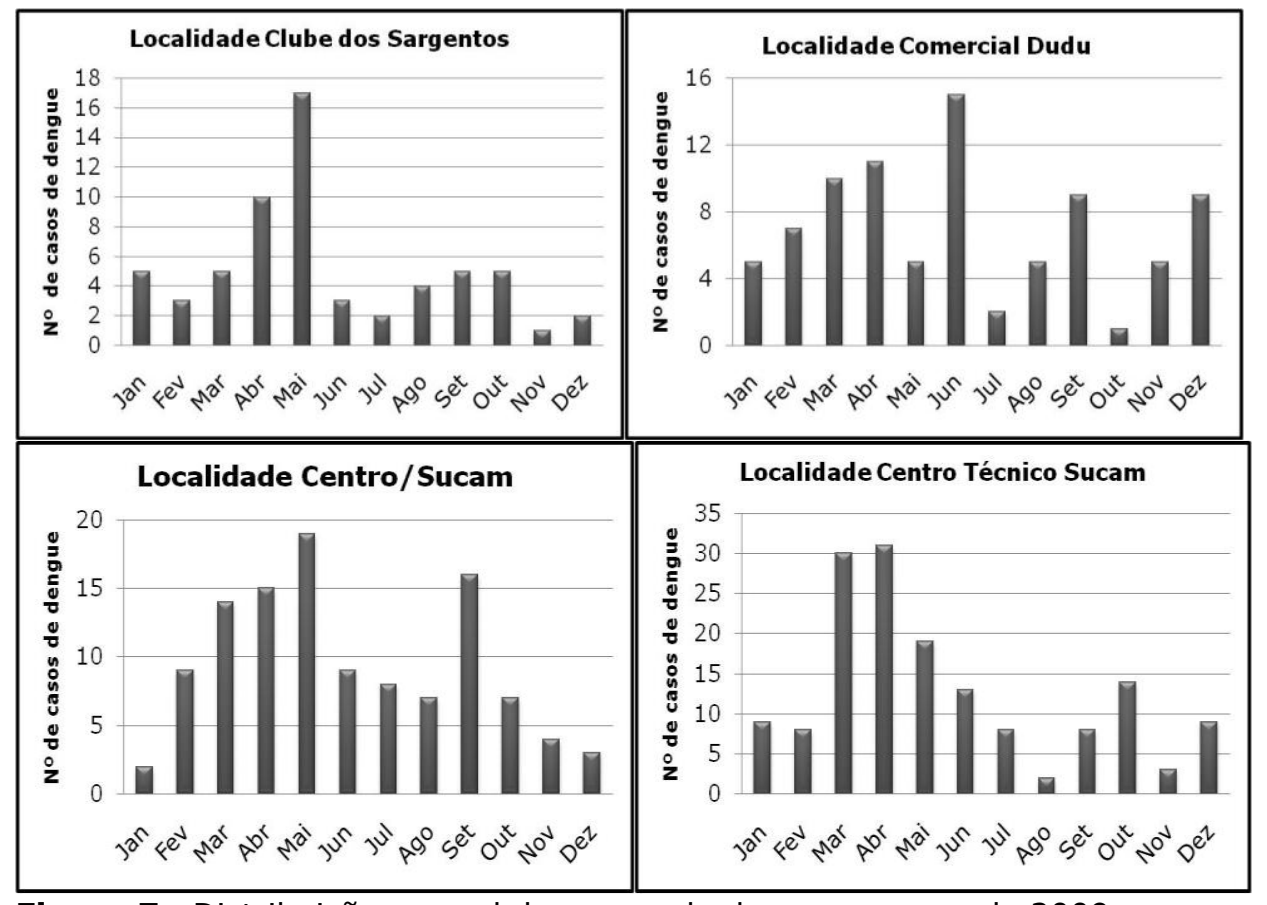

Figura 7- Distribuição mensal dos casos de dengue, no ano de 2009

Fonte de Dados: Secretaria Municipal de Saúde - Vigilância Epidemiológica e Projeto "O Clima Urbano de Jataí" (Laboratório de Climatologia-UFG/Campus Jataí).

Organizado por: PEREIRA, 2010. 
O número de casos de dengue nos anos de 2007 e 2009 apresentou um panorama de crescimento, passando de 224 para 413 casos respectivamente. 0 ano de 2009 os casos ocorreram em todos os meses. Já em 2008 constatou-se 66 casos. Embora haja uma política no combate a dengue, esta apresenta de forma cíclica, pois um ano temos muitos casos (epidemia) e o outro diminuiu ocorrência sucessivamente a partir de 2005.

\section{Espacialização dos casos de dengue no perímetro urbano}

A geografia da dengue em Jataí se apresenta de forma bastante intensa, tendo uma distribuição em vários bairros da cidade, conforme as figuras 9, 10 e 11. No período de 2007 a 2009, dos 78 bairros que compõe a malha urbana da cidade, os bairros Centro (87 casos), Aeroporto (39 casos) e Vila Fátima (49 casos) apresentaram os maiores casos de dengue. A concentração nesses bairros deve-se a predominância de terrenos vagos que em sua maioria são locais de depósitos de lixo para a população (figura 8), além do padrão predial e econômico de renda alta.

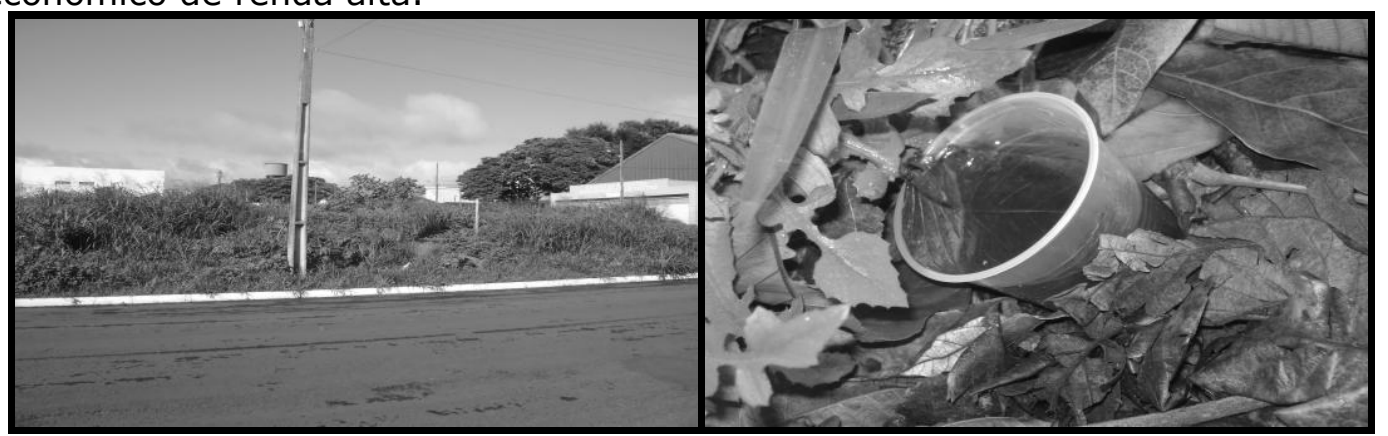

Figura 8 - Presença de lote vago e recipiente com água acumulada da chuva. Foto: Mariano, 2008.

No ano de 2007, os bairros que apresentaram 224 casos. As maiores ocorrência concentraram no Centro (35 casos), no bairro Colméia Park (22 casos) e a Vila Fátima (19 casos), totalizando 76 casos e correspondendo a $34 \%$, apresentados na figura 9.

No ano de 2008, com 66 casos de dengue, os bairros com maior número de casos foram: Aeroporto (8), Antena (5) e Estrela Dalva (4), correspondendo a $26 \%$ dos casos. O bairro Aeroporto esta representado nas classes 6 a 10, na figura 10. Embora este ano apresentasse um valor baixo em relação ao ano de 2007 e 2009, estes valores também ocorreram em vários bairros da cidade. 


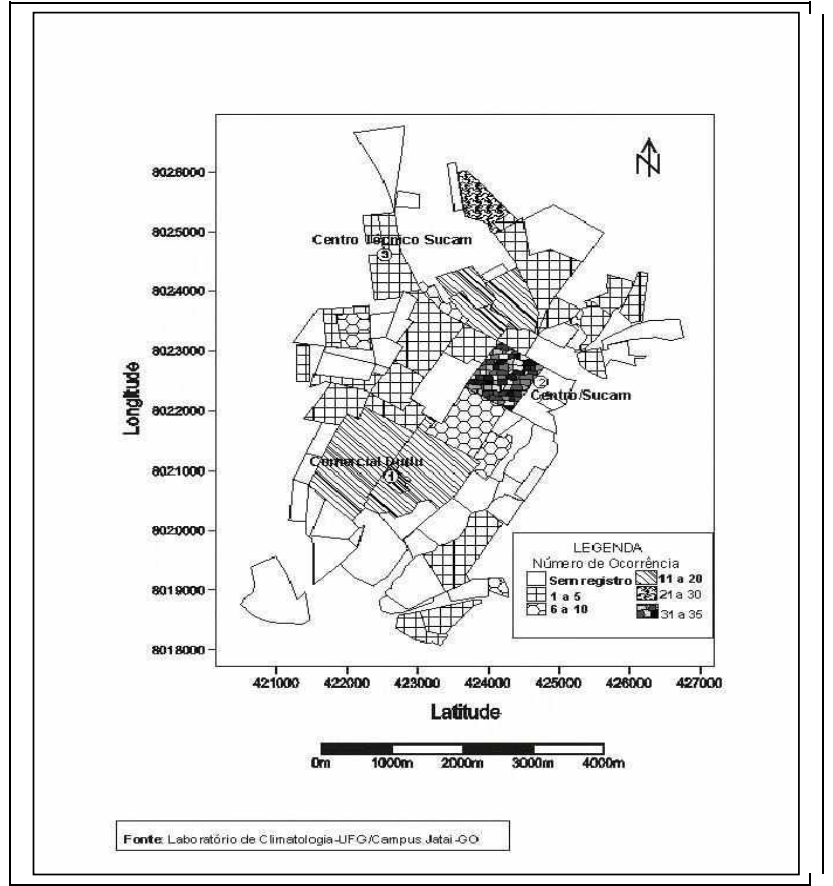

Figura 9 - Distribuição da dengue nos bairros da cidade de Jataí-GO (2007).

Fonte de Dados: Secretaria Municipal de Saúde - Vigilância Epidemiológica e Projeto "O Clima Urbano de Jataí" (Laboratório de Climatologia-UFG/Campus Jataí).

Organizado por: MARIANO, 2010.

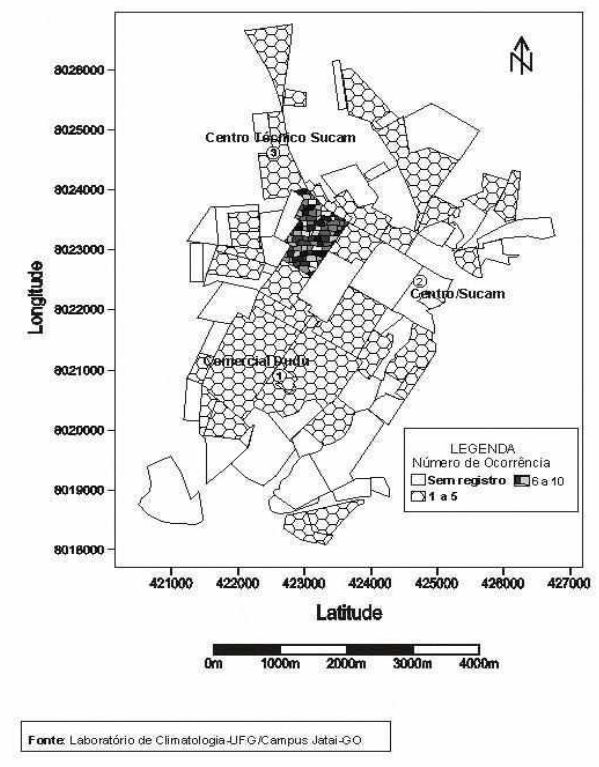

Figura 10 - Distribuição da dengue nos bairros da cidade de Jataí-GO (2008).

Fonte de Dados: Secretaria Municipal de Saúde - Vigilância Epidemiológica e Projeto "O Clima Urbano de Jataí" (Laboratório de Climatologia-UFG/Campus Jataí).

Organizado por: MARIANO, 2010. 
No ano de 2009, com 413 casos de dengue, as localidades Centro Técnico Sucam e Centro Sucam apresentaram 267 casos, representando 65\%. Os bairros com maior número de casos foram: Centro (52), Aeroporto (31) e Vila Fátima e Santa Maria (30), correspondendo a $35 \%$ dos casos, que são bairros caracterizados por apresentar muitos terrenos vagos e muito lixo, Figura 11.

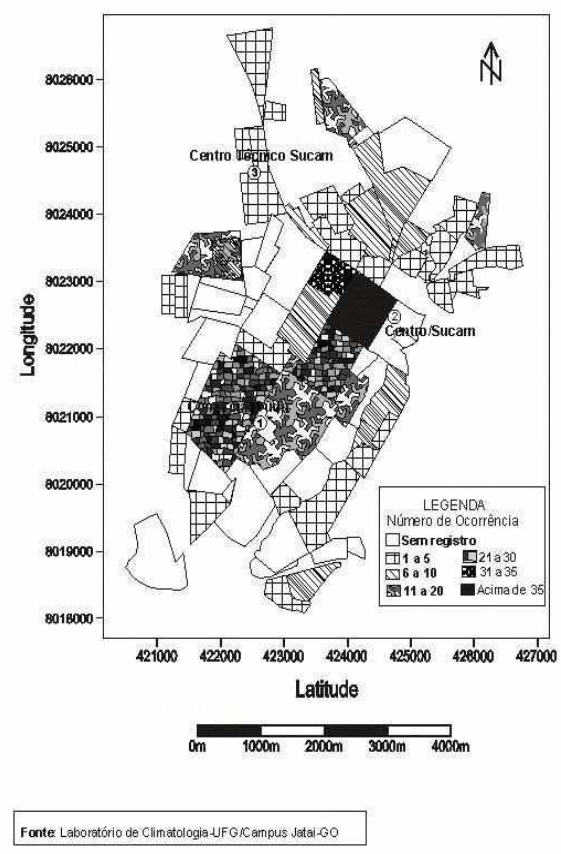

Figura 11 - Distribuição da dengue nos bairros da cidade de Jataí-GO (2009).

Fonte de Dados: Secretaria Municipal de Saúde - Vigilância Epidemiológica e Projeto "O Clima Urbano de Jataí" (Laboratório de Climatologia-UFG/Campus Jataí).

Organizado por: MARIANO, 2010.

\section{CONCLUSÕES}

No período de 2007 a 2009, ocorreu grande variabilidade na distribuição da dengue nos bairros, sendo que os maiores números de casos se concentraram na região do Centro Técnico Sucam, com 181 de ocorrências, de um total de 703 casos registrados.

O bairro Centro e Vila Fátima foram os bairros nos quais tiveram o maior número de casos, registrando 49 e 89 casos de dengue respectivamente, seguido pelo Aeroporto com o registro de 39 casos de dengue.

O Centro Sucam e Centro Técnico Sucam apresentaram os maiores casos de dengue para o período, 218 e 241 respectivamente.

O mês de março apresentou o maior índice pluviométrico, acima de 320 $\mathrm{mm}$, e o período de abril e maio maior índice de ocorrência da doença da dengue, 109 e 107 respectivamente. Embora o mês de março fosse o mais 
chuvoso, os maiores casos de dengue começam após o mês de março, pois é neste período há uma diminuição das chuvas e o acúmulo de água nos recipientes e a diminuição do escoamento superficial favorecendo a proliferação, confirmados por Silva (2006 e 2007).

O número de casos de dengue nos anos de 2007 e 2009 apresentou um panorama de crescimento, passando de 224 para 413 casos. No ano de 2009 em todos os meses houve casos de dengue. Já em 2008 ocorreram 66 casos, pois embora haja uma política no combate a dengue, esta apresenta de forma cíclica: um ano apresenta muitos casos (epidemia) e o outro há uma diminuição sucessiva a partir de 2005.

A partir dos resultados obtidos, consideramos que o principal mosquito transmissor da dengue vem, ao longo do tempo, se adaptando ao meio urbano. Os maiores índices de casos de dengue em Jataí seguem um padrão sazonal na estação do verão e outono, principalmente nos meses de março, abril e maio com condições ambientais propiciam ao desenvolvimento dos ovos do mosquito Aedes aegypti.

\section{REFERENCIAS BIBLIOGRÁFICAS}

ASSIS, et al. Aplicações de estatística à climatologia: teoria e prática. Pelotas-SP: Editora Universitária, 1996.p.17-19.

AYOADE, J.O. O clima e o homem. In: Introdução a climatologia para os trópicos. Rio de Janeiro: Bertrand, 1991.p. 286-321.

CONFALONIERA, U. E.C. Variabilidade climática, vulnerabilidade social e saúde no Brasil. Terra Livre, São Paulo, v.1, n. 20, p.193-204, jan/jul. 2003.

COSTA, M. A. R. A ocorrência do Aedes aegypti na região Noroeste do Paraná: um estudo sobre a epidemia da dengue em Paranavaí - 1999, na perspectiva da geografia médica. 2001. 214 f. Dissertação (Mestrado Institucional em Geografia). Universidade Estadual Paulista - Faculdade Estadual de Educação Ciências e Letras de Paranavaí. Presidente Prudente, 2001.

PAULA, R.Z.R. A Influência da vegetação no conforto térmico do ambiente construído. 2004. 119 f. Tese (Engenharia Civil, Arquitetura e Urbanismo)- UNICAMP - Campus de Campinas. Campinas, 2004.

SILVA, J.S, MARIANO. Z. de F, SCOPEL.I. A influência do clima urbano na proliferação do mosquito Aedes Aegypti em Jataí (GO) na perspectiva da geografia médica, HYGEIA, Revista Brasileira de Geografia Médica e da Saúde, Uberlândia, v. 2. n. 5, p. 33-46, 2007. Disponível em: www.hygeia.ig.ufu.br/. Acesso em: 20 jan. 2008.

SPERANDIO, T. M; PINTTON, S. E. C. As chuvas e a dengue em Piracicaba- SP: uma abordagem geográfica. In: SIMPÓSIO BRASILEIRO DE CLIMATOLOGIA GEOGRÁFICA, 6, 2004. Aracaju-SE. Anais... Aracaju-SE: UFS, 2004, p. 219. 